\title{
Effects of L-DOPA Pretreatment on the Kinetics, Migration and Carbon Ion Radiation Response of T98G Cells
}

\author{
ANGELICA FACOETTI $^{1^{*}}$, MIRIAM CAVAGNINI ${ }^{1 *}$, MARIO CIOCCA $^{1}$, ROSANNA NANO $^{2}$, \\ FRANCESCA PASI ${ }^{3}$, CARLO APRILE $^{1}$, LORENZO LODOLA $^{4}$, MARCO GIOVANNI PERSICO ${ }^{4,5}$, \\ MANUELA MARENCO ${ }^{4}$, FRANCESCA VALVO $^{1}$ and ROBERTO ORECCHIA ${ }^{1,6}$ \\ ${ }^{1}$ Fondazione CNAO, Pavia, Italy; \\ ${ }^{2}$ Department of Biology and Biotechnology "L. Spallanzani”, University of Pavia, Pavia, Italy; \\ ${ }^{3}$ Oncological Radiotherapy Unit, IRCCS Fondazione Policlinico San Matteo, Pavia, Italy; \\ ${ }^{4}$ Nuclear Medicine Unit, IRCCS Fondazione Policlinico San Matteo, Pavia, Italy; \\ ${ }^{5}$ University School for Advanced Studies IUSS Pavia, Pavia, Italy; \\ ${ }^{6}$ European Institute of Oncology, Milan, Italy
}

\begin{abstract}
Background/Aim: Glioblastoma is the most malignant and widespread brain tumor in adults, with a rapid clinical course. Recently, it has been hypothesized that $L$ DOPA plays a role in the diagnosis and treatment of glioblastoma. The aim of this study was to assess the effects of pretreatment with L-DOPA on the biological behavior of human T98G cells in vitro. Materials and Methods: T98G cells were treated with $50 \mu \mathrm{g} / \mathrm{ml}$ or $100 \mu \mathrm{g} / \mathrm{ml}$ of L-DOPA for $4 \mathrm{~h}$ and their morphology, growth rate, clonogenic survival and migratory capacity in basal conditions and after carbon ion irradiation were evaluated using standard methods. Results: Treated cells showed a lower growth rate and an increased migratory capacity that correlated with the dose of tested L-DOPA . Treatment with L-DOPA increased the growth rate of carbon ion irradiated T98G cells compared to control non-treated cells exposed to the same radiation dose. Conclusion: Our results open further questions about the overall advantage of L-DOPA treatment of glioblastoma.
\end{abstract}

Glioblastoma (GBM) is the most common and aggressive malignant brain tumor in adults, known for its aggressive proliferation and extensive invasion to normal tissue before any symptoms are presented, with long-term survival being extremely rare $(1,2)$.

\footnotetext{
*These Authors contributed equally to this study.

Correspondence to: Facoetti Angelica, Fondazione CNAO, Strada Campeggi 53, Pavia, Italy. Tel: +39 0382078455, Fax: +39 0382078903, e-mail: Facoetti@cnao.it
}

Key Words: Glioblastoma, L-DOPA, ${ }^{18} \mathrm{~F}-\mathrm{DOPA}$, carbon ion radiation, migration, proliferation.
Surgery is the first and most important treatment in these tumors and must be as radical as possible. The infiltration of GBM cells into the surrounding parenchyma makes complete surgical removal almost impossible without producing significant neurological damage and residual cells at the margins of the tumor frequently give rise to recurrences (3). While the introduction of temozolomide into first-line standard of care achieved some survival improvement, nearly all patients relapse within few months and treatment options for recurrent disease remain limited and largely ineffective. Even under optimal circumstances with the use of 'state of the art' diagnostic and therapeutic interventions, less than $15 \%$ of patients will survive 5 years (4).

${ }^{18} \mathrm{~F}$ labelled large neutral amino acids (LNAA) such as FET and DOPA are among the most frequently used PET tracers in glioma diagnosis and monitoring. Albeit the metabolic pathway of positron-labelled LNAA is different, they share a saturable carrier mechanism through the blood-brain barrier. ${ }^{18} \mathrm{~F}$-DOPA is physiologically taken up by the basal ganglia because of the presence of aromatic amino acid decarboxylase activity. Several studies have demonstrated an association between F-DOPA uptake and glioma grading, progression-free-survival and overall survival. In comparison with FET, however, the uptake in glioma and tumor-to-brain ratios are lower (5).

Similar to neurosurgical resection, radiotherapy is one of the most important local treatment options and is the main treatment component for both newly diagnosed and relapsed brain tumors. However, developments in x-ray external-beam radiation therapy in terms of increased precision of dose delivery over the last two decades have failed to offer markedly improved outcomes for GBM patients. As a result, other treatment modalities are being investigated and optimized for high-grade gliomas. Boron neutron capture 
therapy (BNCT) is an experimental biochemically-targeted radiotherapy based on the nuclear capture and fission reactions that occur when non-radioactive ${ }^{10} \mathrm{~B}$ is irradiated with low energy thermal neutrons to yield high linear energy transfer alpha particles and recoiling ${ }^{7} \mathrm{Li}$ nuclei. Therefore, BNCT enables the application of a high dose of particle radiation selectively to tumor cells in which ${ }^{10} \mathrm{~B}$ compound has been accumulated (6). For its physical and radiobiological features BNCT appears theoretically very suitable for GBM, although the success of this technique depends on a sufficient amount of ${ }^{10} \mathrm{~B}$ in tumour cells and differential uptake of ${ }^{10} \mathrm{~B}$ in tumour versus normal cells. Several in vitro and in vivo studies have recently proposed L-DOPA pretreatment with the aim of increasing the efficiency of Boronophenylalanine (BPA) incorporation into glioma tumor cells $(7,8)$.

Starting from these clinical and experimental applications of L-DOPA, we investigated the effects of L-DOPA treatment on different cellular aspects of GBM T98G cells in order to evaluate the tumour cells response to this catecholamine, even after high LET radiation exposure.

\section{Materials and Methods}

Cell culture and growth curves. Human glioblastoma T98G cells were cultured in Eagle's minimum essential medium (EMEM) supplemented with $10 \%$ fetal bovine serum, $1 \%$ penicillin and streptomycin at $37^{\circ} \mathrm{C}$ in humidified atmosphere containing $5 \% \mathrm{CO}_{2}$. All cell culture media, supplements and chemicals were purchased from Sigma-Aldrich (St. Louis, MO, USA).

Morphological analysis. Immediately after L-DOPA treatment, cells were fixed for $10 \mathrm{~min}$ with $3.7 \%$ formalin, washed with PBS, stained with Gentian violet solution for 10 minutes, washed and observed using a light microscope.

Cell proliferation and doubling time calculation. In order to evaluate cell growth, cells were seeded at the density of $2 \times 10^{5}$ cells/well. After 24,48 and $72 \mathrm{~h}$ cells were detached and counted using trypan blue cell exclusion assay. Three independent experiments were performed. Growth curves were plotted to determine the exponential phase of growth of the cells at each seeding density. The doubling time was calculated using the following formula:

$\mathrm{DT}=($ time $\times \log (2) /(\log ($ final concentration $)-\log ($ initial concentration $)$

L-DOPA treatment. L-DOPA powder (Alfa Aesar, MA, USA) was dissolved in EMEM to generate a stock solution of $0.001 \mathrm{~g} / \mathrm{ml}$, concentration $0.005 \mathrm{M}$. The stock solution was diluted 1:10 before use.

T98G cells in the exponential growth phase were treated for $4 \mathrm{~h}$ with $100 \mu \mathrm{g} / \mathrm{ml}, 50 \mu \mathrm{g} / \mathrm{ml}$ or $0 \mu \mathrm{g} / \mathrm{ml} \mathrm{L}$-DOPA in complete medium at $37^{\circ} \mathrm{C}$ in humidified atmosphere containing $5 \% \mathrm{CO}_{2}$. Subsequently, cells were washed with PBS and processed for successive analysis.

Carbon ion irradiation. Carbon ion irradiations were performed with the clinical beam at the CNAO Foundation in Pavia. Cells were vertically irradiated in T12.5 flasks inside a water phantom put at the isocenter on the treatment table, at the depth of $15 \mathrm{~cm}$, corresponding to the mid spread-out Bragg peak (SOBP). The SOBP $(6 \mathrm{~cm}$ width, from 12 to $18 \mathrm{~cm}$ depth in water) was achieved with active beam energy modulation (9). Samples were irradiated at 0,2 and 4 Gy.

Wound healing assay. To monitor the collective motion of the cells in two dimensions the wound healing assay was performed. $4 \times 10^{5}$ T98G cells per well (12 well plate, FALCON ${ }^{\circledR}$ ) were seeded and cultured over night at $37^{\circ} \mathrm{C}$ in humidified atmosphere containing $5 \%$ $\mathrm{CO}_{2}$. Cells were then pretreated with L-DOPA for $4 \mathrm{~h}$, and subsequently the wound was created using a $200 \mu$ l pipette tip. The media containing cell debris was carefully aspirated and replaced with fresh complete medium. At 0,18 and $22 \mathrm{~h}$ after wound creation pictures were taken to check for wound closure. The closed distance at these time points was measured with ImageJ software and compared to control conditions. Three independent experiments were performed.

Based on the width of the wound, we calculated the migration distance and the speed of cell migration $(10,11)$ The cell migration rate, $\mathrm{v}_{\text {migration }}$, is the average velocity at which the cells collectively move into the gap.

Slope $=d A / d t$

where the area (A) is the width of the gap (w) times the length of the gap (1). Assuming that the gap is much longer than the field-ofview so that cells do not migrate in from the edges, the length is constant, so:

$d A / d t=d w / d t * l$

Also, the width closes in at twice the rate of the cell migration, so

$d w / d t=2 * \mathrm{v}_{\text {migration }}$

This gives the cell migration rate as:

$\mathrm{v}_{\text {migration }}=\mid$ slopel $/ 2 * l$

Carbon ion irradiations were performed immediately before seeding cells into the wells. Individual cell's morphological characteristics during migration were also evaluated by means of Gentian violet staining.

Transwell migration assay. 3D-migration of $\mathrm{T} 98 \mathrm{G}$ cells was assessed through transwell chambers containing a membrane with a pore size of $8 \mu \mathrm{m}$ (Cell Culture Insert, FALCON ${ }^{\circledR}$ ). $2 \times 10^{5}$ treated cells were seeded in the upper chambers and $1.5 \mathrm{ml}$ of medium was placed in the lower wells. After $24 \mathrm{~h}$ at $37^{\circ} \mathrm{C}$ in humidified atmosphere containing $5 \% \quad \mathrm{CO}_{2}$, the cells that reached the undersurface of the transwell membrane were fixed with $70 \%$ cold ethanol and stained with Gentian violet. Three independent experiments were performed. The number of migrated cells was counted under an optical microscope in five randomly selected fields at 400x magnification and results are reported as mean \pm standard deviation $(\mathrm{SD})$.

Clonogenic survival assay. The assessment of the effect of L-DOPA pretreatment on the clonogenic survival after carbon ion irradiation 



Figure 1. Cell growth curves. A) T98G cells were treated for $4 \mathrm{~h}$ with $100 \mu \mathrm{g} / \mathrm{ml}$ (dark grey), or $50 \mu \mathrm{g} / \mathrm{ml}$ (light grey) L-DOPA and subsequently the number of viable cells was evaluated at different time points and compared with that of control cells $(0 \mu \mathrm{g} / \mathrm{ml} ; \mathrm{black}) . B)$. T98G cells were pretreated for $4 \mathrm{~h}$ with $100 \mu \mathrm{g} / \mathrm{ml}$ (dark grey), $50 \mu \mathrm{g} / \mathrm{ml}$ (light grey) or $0 \mu \mathrm{g} / \mathrm{ml}$ (black) of L-DOPA and irradiated with 2 or 4 Gy. Differences among groups are all statistically significant.

was performed by means of clonogenic assay. Immediately after carbon ion irradiation, sub confluent cultures were rinsed with PBS and trypsinized. Cells were counted and reseeded into five $60-\mathrm{mm}$ dishes for each dose/treatment at a suitable concentration and incubated for 14 days. Afterward colonies were fixed with ethanol, stained with Crystal violet solution and counted. Only colonies containing more than 50 cells were considered as survivors. Surviving fractions relative to the untreated samples were determined and plotted on a semilog scale as a function of the dose. Three independent experiments were performed.

Statistical analysis. Data were expressed as mean \pm SD of separate experiments $(n \geq 3)$ and compared by one-way analysis of variance (ANOVA) followed by Student's $t$-test (GraphPad Software, La Jolla, CA, USA). Difference between two treatments was considered statistically significant at $p<0.05$.

\section{Results}

Morphology. T98G cells treated for $4 \mathrm{~h} 100 \mu \mathrm{g} / \mathrm{ml}$ or $50 \mu \mathrm{g} / \mathrm{ml}$ of L-DOPA were stained with Gentian violet to evaluate under a light microscope any effects on the cellular morphology compared to control conditions (complete medium). This treatment induced some morphological alterations on T98G cells. In particular, the cells in control conditions had a fusiform, fibroblastic-like morphology and were forming clusters whereas cells treated with $100 \mu \mathrm{g} / \mathrm{ml}$ or $50 \mu \mathrm{g} / \mathrm{ml} \mathrm{L}$ DOPA showed a lower tendency to aggregate and a more roundish morphology.

Cell growth curves. T98G cells treated for $4 \mathrm{~h}$ with $100 \mu \mathrm{g} / \mathrm{ml}$ or $50 \mu \mathrm{g} / \mathrm{ml} \mathrm{L-DOPA}$ and the number of viable cells was evaluated at different time points and compared with nontreated control cells $(0 \mu \mathrm{g} / \mathrm{ml})$.
Non-treated T98G cells showed a higher growth rate compared to treated cells, which appeared to be related to the L-DOPA concentration. The growth curve of cells treated with $50 \mu \mathrm{g} / \mathrm{ml}$ had a slope of 5562.5 , while that of cells treated with $100 \mu \mathrm{g} / \mathrm{ml}$ of 3390.8 , compared to 7640.6 of non-treated cells (Figure 1A). Regarding the duplication time, in non-treated cells was $10 \mathrm{~h}$, and in cells treated with $50 \mu \mathrm{g} / \mathrm{ml}$ or $100 \mu \mathrm{g} / \mathrm{ml}$ L-DOPA was $12 \mathrm{~h}$ and $19 \mathrm{~h}$, respectively.

In order to evaluate whether L-DOPA pretreatment could affect the growth pattern of T98G GBM cells following carbon ion irradiation, the in vitro growth curve of cells treated with $50 \mu \mathrm{g} / \mathrm{ml}$ or $100 \mu \mathrm{g} / \mathrm{ml}$ of L-DOPA was calculated and compared to that of control cells. The results from these experiments, presented in Figure 1B, indicated that treatment with L-DOPA increased the growth rate of T98G cells after irradiation with 2 and 4 Gy of carbon ions. This effect was dose dependent: the higher the dose, the faster the growth rate.

Scratch assay. The scratch assay pointed out that in all the experimental conditions tested T98G cells are able to restore the monolayer over the time. However, as illustrated in Figure 2A, that the non-treated cells (control) covered the wound area at a lower rate compared to the treated cells. This result was confirmed by the digital quantification of the free area as shown in Figure 2B. The cells migration rate was calculated $18 \mathrm{~h}$ after the formation of the scratch: The migration rate of the non-treated cells was $25 \mu \mathrm{m} / \mathrm{h}$, while that of cells treated with $50 \mu \mathrm{g} / \mathrm{ml}$ was $38 \mu \mathrm{m} / \mathrm{h}$ and that of cells treated with $100 \mu \mathrm{g} / \mathrm{ml}$ was $45 \mu \mathrm{m} / \mathrm{h}$.

The scratch assays performed with carbon ion irradiated cells, revealed that irradiation with either 2 or $4 \mathrm{~Gy}$ of 
A


T18


T22
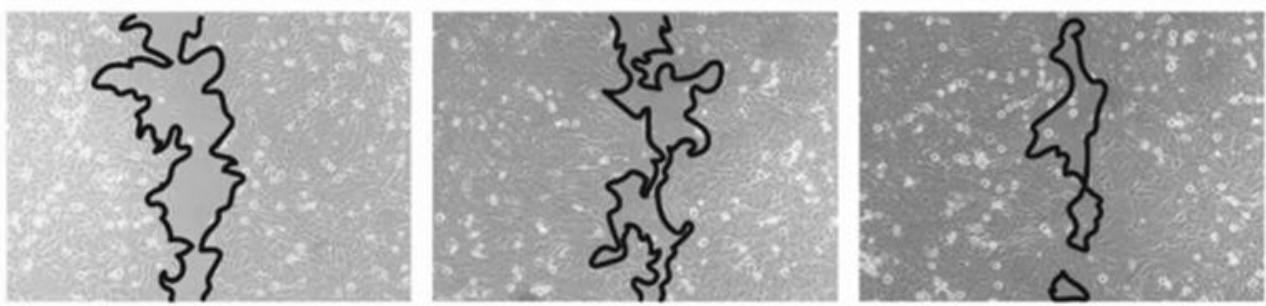

B

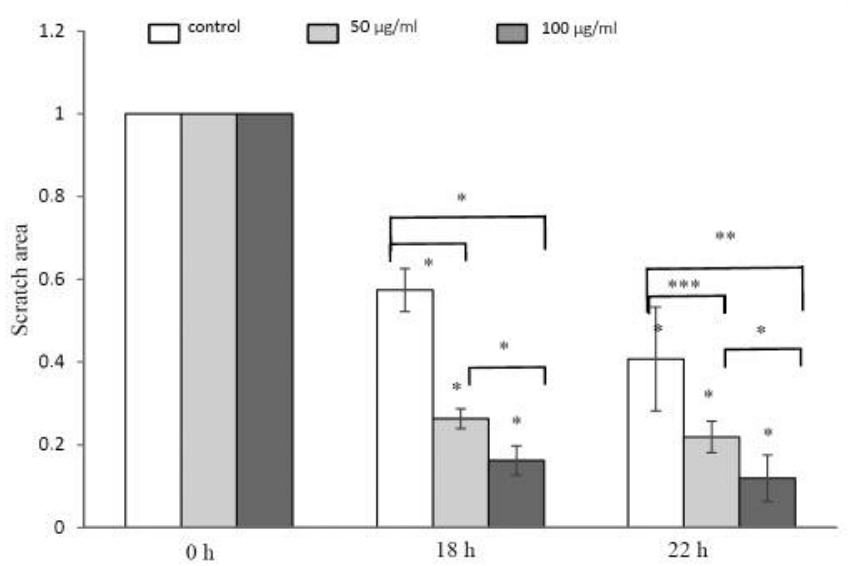

Figure 2. Wound-healing assay. A) Representative images of the wound area captured 0 (T0), 18 (T18) and $22 h$ (T22) from the formation of the scratch. B) Quantification of the free areas at 0,18 and $22 \mathrm{~h}$ from the formation of the wound normalized with respect to the reference control. $p$-Values: $* 0.0001 ; * * 0.006$; ***0.003.

carbon ions is able to increase the efficiency with which these cells restore the confluent monolayer. This effect was dependent on the dose of radiation: the higher the dose, the greater the speed with which the cells reconstitute the monolayer. The quantification of the free areas at 0,15 and $24 \mathrm{~h}$ from the formation of the wound normalized with respect to the reference control, are shown in Figure 3.

No-pretreated irradiated cells reduced the free area with an efficacy that is not correlated with the dose. Pre-treated irradiated cells showed heterogeneous responses. Pretreatment with $50 \mu \mathrm{g} / \mathrm{ml}$ of L-DOPA speed-up the migration of both $2 \mathrm{~Gy}$ and 4Gy-irradiated T98G cells, compared to control cells $(0$ $\mu \mathrm{g} / \mathrm{ml})$. Whereas pretreatment with $100 \mu \mathrm{g} / \mathrm{ml}$ decreased the ability of cells to close the wound.

Transwell migration assays. The transwell migration test confirmed a significant increase in the migratory capacity of T98G cells treated with L-DOPA. The number of T98G cells that migrated to the lower surface of the insert was counted and compared to that of control cells (Figure 4). 

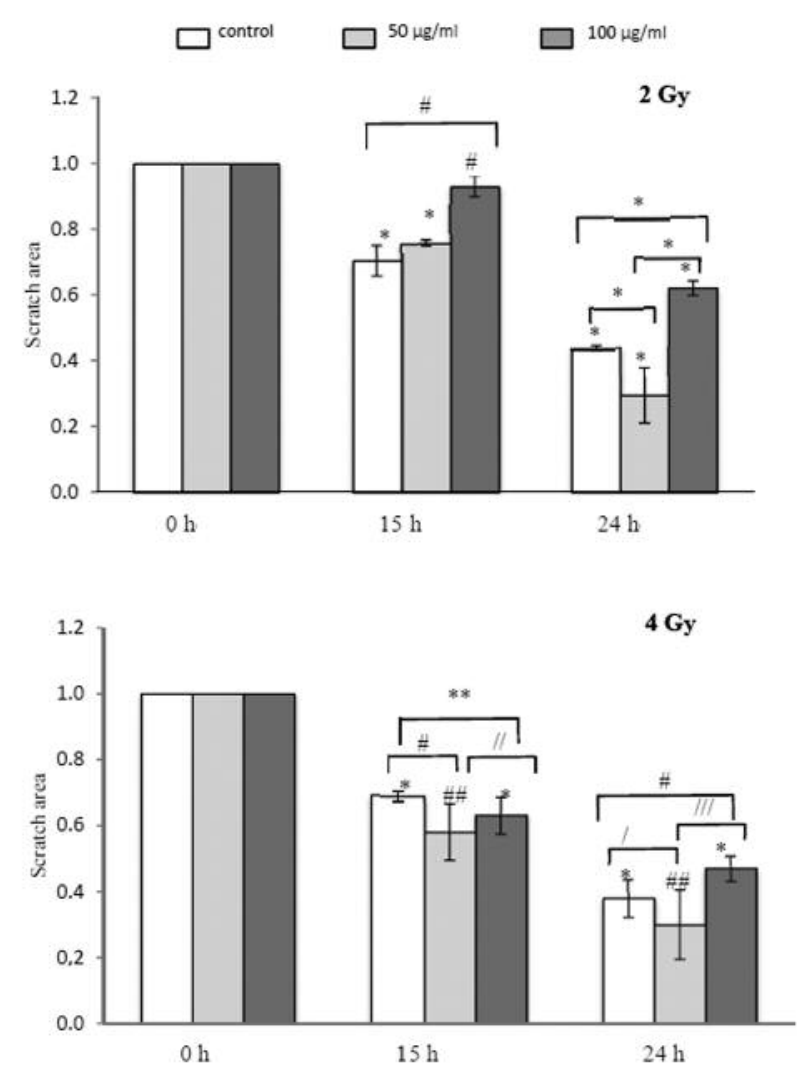

Figure 3. Wound healing assay with pretreated and irradiated $T 98 G$ cells. T98G cells were pretreated for $4 \mathrm{~h}$ with $100 \mu \mathrm{g} / \mathrm{ml}$ (dark grey), or $50 \mu \mathrm{g} / \mathrm{ml}$ (light grey) L-DOPA and subsequently irradiated with 2 or 4 Gy carbon ions. Quantification of the free areas at 0, 15 and $24 \mathrm{~h}$ from the formation of the wound. p-Values: *0.0001; **0.01; \#0.02; \#\#0.0002; /0.03; //0.04; ///0.007.

Clonogenic survival. A preliminary analysis was performed on the ability of T98G cells to form colonies under the different experimental conditions tested. The curves in Figure 5 represent the clonogenic survival fractions of T98G cells pretreated with L-DOPA according to the dose of carbon ion administered. Although some values do not reach a level of significance due to large $\mathrm{SD}$, a trend is observed suggesting that both doses of L-DOPA pretreatment make T98G cells more resistant to carbon ion irradiation and this L-DOPAinduced radioresistance appears to be correlated to the dose of catecholamine: the higher the dose tested $(100 \mu \mathrm{g} / \mathrm{ml})$, the greater radioresistance.

\section{Discussion}

Recently, a role of L-DOPA in the diagnosis and treatment of GBM has been hypothesized. In the diagnostic field, evaluation by PET imaging of glioma-suspicious lesions is conducted by means of mainly 4 radiotracers: the glucose analogue $\left[{ }^{18} \mathrm{~F}\right] \mathrm{FDG}$ and the radiolabeled amino acids $\left[{ }^{11} \mathrm{C}\right] \mathrm{MET},\left[{ }^{18} \mathrm{~F}\right] \mathrm{FET}$, and DOPA (12). 3,4-dihydroxy-6- $\left[{ }^{18} \mathrm{~F}\right]-$ fluoro-L-phenylalanine ([ $\left.\left[{ }^{18} \mathrm{~F}\right] \mathrm{DOPA}\right)$ is an ${ }^{18} \mathrm{~F}$-labeled dopamine precursor, which was primarily developed to measure dopamine synthesis in the basal ganglia, is attractive for imaging of suspected tumor recurrence, because as opposed to contrast-enhanced MRI, ${ }^{18}$ FDOPA-PET is believed to require active transport mechanisms for tissue uptake rather than to depend on blood-brain barrier breakdown (13).

Published data show that ${ }^{18} \mathrm{~F}$-DOPA provides more accurate visualization of high-grade, low-grade, and recurrent tumors in comparison to the radiotracers 2-deoxy-2- ${ }^{18} \mathrm{~F}$-fluoro-D-glucose ( ${ }^{18} \mathrm{~F}$-FDG) or 3-deoxy-3- ${ }^{18} \mathrm{~F}$-fluorothymidine $\left({ }^{18} \mathrm{~F}\right.$-FLT) (14).

Chemoradiation-induced pseudoprogression and/or necrosis identified by MRI is indistinguishable from tumor recurrence on conventional contrast-enhanced MRI. However, while early progressive disease indicates treatment failure and necessitates a change in therapy, post-treatment radiation effects indicate success of the treatment. Therefore, determination of early progressive disease versus posttreatment radiation effects is vital. Numerous studies have investigated novel imaging modalities and parameters to distinguish post-treatment radiation effects from early progressive disease. Thus, there is significant interest in using ${ }^{18}$ F-DOPA PET in conjunction with traditional magnetic resonance imaging (MRI) for neurosurgical and radiation therapy planning in gliomas (15-17).

The increased uptake of MET, FET and FDOPA in gliomas and brain metastases appears to be caused predominantly by increased transport via the amino acid transport system, L for large neutral amino acids, namely the subtypes LAT1 and LAT2 $(15,18-20)$. A feature that distinguishes FET from MET and FDOPA is the high metabolic stability of FET. After the transport via L-type amino acid transporters into tumor tissue, it has been demonstrated that MET and FDOPA show some metabolic degradation and incorporation into protein or participation in other metabolic pathways (21), whereas FET is not metabolized (22). Furthermore, it has been shown that overexpression of LAT1 is closely correlated with a malignant phenotype and proliferation of gliomas $(23,24)$.

Recent literature encourages the potential use of L-DOPA in BNCT of brain tumors because of L-DOPA's ability to induce a significant enhancement of BNCT effectiveness without remarkable associated side effects. Indeed, $4 \mathrm{~h}$ preload with L-DOPA has been described to increase incorporation of BPA in tumors both in vivo and in vitro, likely activating the LAT system and thus increasing the efficacy of BNCT. Specifically, it was demonstrated that LDOPA pre-administration in the C6 glioma model gave rise to a 2.7-times increase of BPA tumour accumulation with respect to that of controls $(7,8)$. 




Figure 4. Transwell migration test of T98G cells pretreated with $100 \mu \mathrm{g} / \mathrm{ml}$ (dark grey) $50 \mu \mathrm{g} / \mathrm{ml}$ (light grey) or $0 \mu \mathrm{g} / \mathrm{ml}$ (black) of L-DOPA. The number of T98G cells migrated on the lower surface of the insert were counted.p-Values: *0.0001; **0.0025. Below microphotographs of migrated T98G cells under control conditions, with pre-treatment with $50 \mu \mathrm{g} / \mathrm{ml}$ and $100 \mu \mathrm{g} / \mathrm{ml}$ at $\times 400 \mathrm{magnification} \mathrm{fixed} \mathrm{and} \mathrm{stained} \mathrm{with} \mathrm{Gentian} \mathrm{violet.}$

From the diagnostic point of view this approach looks very appealing because in theory it could be employed to increase the tumor accumulation of ${ }^{18} \mathrm{~F}$-DOPA in PET diagnostics.

In this study, the effects of L-DOPA pretreatment on the behavior of T98G human glioblastoma cell line were investigated.

Our results pointed out that L-DOPA pretreatment, at the concentrations suggested in the literature $(7,8)$ induces significant changes in T98G cells behavior: a decrease in cell proliferation with a minor tendency to aggregate is associated to higher migration rates, both as collective motion of the cells in two dimensions (wound healing assay) and as single cell migration (transwell assay). Pronounced effects of L-DOPA pretreatment of T98G cells were observed on the response to carbon ion irradiation. Pretreated T98G cells showed a significant increase in migration capability and in carbon ions radiation resistance.

Glioblastoma cells either in vitro and in vivo are able to incorporate tyrosine and DOPA and there is evidence that they are able to synthetize and secret dopamine in an autocrine fashion (25). Whether the effects described in this study are due to L-DOPA itself or to newly-synthetized dopamine is a



Figure 5. Colony formation assay of T98G cells pretreated with $100 \mu \mathrm{g} / \mathrm{ml}$ (dark grey), $50 \mu \mathrm{g} / \mathrm{ml}$ (light grey) or $0 \mu \mathrm{g} / \mathrm{ml}$ (black) of L-DOPA and irradiated with 0,2 or 4 Gy of carbon ions. * $p=0.08$; \# $p=0.06$.

matter of debate. However, the effects of dopamine on isolated glioma U87MG and U251 cells (26) are only in part superimposable to those observed in this study. In fact, in both cases a dose-dependent inhibition of cell growth is observed 
as well as a lower tendency to aggregation. On the contrary, L-DOPA-pretreated T98G cells showed more filopodia, increased ability to migrate and cover the wound area. These latter effects are in open contrast to those reported with dopamine. Therefore, our results cannot be attributed to a hypothetical effect of endogenous de novo dopamine synthesis induced by L-DOPA preload.

Our preliminary results obtained in a single cell line, open further questions about the advantage of L-DOPA preload in BNCT. Further studies are necessary to examine the possible application of ${ }^{18} \mathrm{~F}$-DOPA in PET.

\section{Acknowledgements}

This research work was partially founded by INFN project ETHICS

\section{References}

1 Omuro A and DeAngelis LM: Glioblastoma and other malignant gliomas: a clinical review. JAMA 310: 1842-1850, 2013.

2 Okonogi N, Shirai K, Oike T, Murata K, Noda SE, Suzuki Y and Nakano T: Topics in chemotherapy, molecular-targeted therapy, and immunotherapy for newly-diagnosed glioblastoma multiforme. Anticancer Res 35: 1229-1235, 2015.

3 Paw I, Carpenter RC, Watabe K, Debinski W and Lo HW: Mechanisms regulating glioma invasion. Cancer Lett 362: 1-7, 2015.

4 Johnson JM and Chung C: Glioblastoma: does PET shed light to a difficult problem? Transl Cancer Res 5: S680-S683, 2016.

5 Herholz K: Brain Tumors: An Update on Clinical PET Research in Gliomas. Semin Nucl Med 47: 5-17, 2017.

6 Shin-Ichi Miyatake, Shinji Kawabata, Ryo Hiramatsu, Toshihiko Kuroiwa, Minoru Suzuki, Natsuko Kondo and Koji Ono: Boron Neutron Capture Therapy for Malignant Brain Tumors. Neurol Med Chir (Tokyo) 56: 361-371, 2016.

7 Yang W, Barth RF, Huo T, Kabalka GW, Shaikh AL, Haider SA and Chandra S: Effects of L-DOPA pre-loading on the uptake of boronophenylalanine using the F98 glioma and B16 melanoma models. Appl Radiat Isot 88: 69-73, 2014.

8 Capuani S, Gili T, Bozzali M, Russo S, Porcari P, Cametti C, D'Amore E, Colasanti M, Venturini G, Maraviglia B, Lazzarino $\mathrm{G}$ and Pastore FS: L-DOPA preloading increases the uptake of borophenylalanine in C6 glioma rat model: a new strategy to improve BNCT efficacy. Int J Radiat Oncol Biol Phys 72: 562$567,2008$.

9 Facoetti A, Di Gioia C, Pasi F, Di Liberto R, Corbella F, Nano R, Ciocca M, Valvo F and Orecchia R: Morphological analysis of amoeboid-mesenchymal transition plasticity after low and high LET radiation on migrating and invading pancreatic cancer cells. Anticancer Res 38: 4585-4591, 2018.

10 Jonkman JE, Cathcart JA, Xu F, Bartolini ME, Amon JE, Stevens $\mathrm{KM}$ and Colarusso P: An introduction to the wound healing assay using live-cell microscopy. Cell Adh Migr 8: 440-451, 2014.

11 Justus CR, Leffler N, Ruiz-Echevarria M and Yang LV: In vitro cell migration and invasion assays. J Vis Exp 1: 88, 2014.

12 la Fougère C, Suchorska B, Bartenstein P, Kreth FW and Tonn JC: Molecular imaging of gliomas with PET: Opportunities and limitations. Neuro-Oncology 13: 806-819, 2011.
13 Kruser TJ, Mehta MP and Robins HI: Pseudoprogression after glioma therapy: a comprehensive review. Expert Rev Neurother 13: 389-403, 2013.

14 Fueger BJ, Czernin J, Cloughesy T, Silverman DH, Geist CL, Walter MA, Schiepers C, Nghiemphu P, Lai A, Phelps ME and Chen W: Correlation of 6-18F-fluoro-L-DOPA PET uptake with proliferation and tumor grade in newly diagnosed and recurrent gliomas. J Nucl Med 51: 1532-1538, 2010.

15 Youland RS, Kitange GJ, Peterson TE, Pafundi DH, Ramiscal JA, Pokorny JL, Giannini C, Laack NN, Parney IF, Lowe VJ, Brinkmann DH and Sarkaria JN: The role of LAT1 in (18)F-DOPA uptake in malignant gliomas. J Neurooncol 111: 11-18, 2013.

16 Bell C, Dowson N, Puttick S, Gal Y, Thomas P, Fay M, Smith J and Rose S: Increasing feasibility and utility of (18)F-FDOPA PET for the management of glioma. Nucl Med Biol 42: 788-795, 2015.

17 Karunanithi S, Sharma P, Kumar A, Khangembam BC, Bandopadhyaya GP, Kumar R, Goenka A, Gupta DK, Malhotra $\mathrm{A}$ and Bal C: Comparative diagnostic accuracy of contrastenhanced MRI and (18)F-FDOPA PET-CT in recurrent glioma. Eur Radiol 23: 2628-2635, 2013.

18 Okubo S, Zhen HN, Kawai N, Nishiyama Y, Haba R and Tamiya T: Correlation of L-methyl-11C-methionine (MET) uptake with L-type amino acid transporter 1 in human gliomas. J Neurooncol 99: 217-225, 2010

19 Papin-Michault C, Bonnetaud C, Dufour M, Almairac F, Coutts M, Patouraux S, Virolle T, Darcourt J and Burel-Vandenbos F: Study of LAT1 expression in brain metastases: towards a better understanding of the results of positron emission tomography using amino acid tracers. PLoS One 11: e0157139, 2016.

20 Wiriyasermkul P, Nagamori S, Tominaga H, Oriuchi N, Kaira K, Nakao H, Kitashoji T, Ohgaki R, Tanaka H, Endou H, Endo K, Sakurai $\mathrm{H}$ and Kanai Y: Transport of 3-fluoro-L- $\alpha$-methyl-tyrosine by tumor-upregulated L-type amino acid transporter 1: a cause of the tumor uptake in PET. J Nucl Med 53: 1253-1261, 2012.

21 Singhal T, Narayanan TK, Jain V, Mukherjee J and Mantil J: ${ }^{11} \mathrm{C}-$ L-methionine positron emission tomography in the clinical management of cerebral gliomas. Mol Imaging Biol 10: 1-18, 2008.

22 Langen KJ, Jarosch M, Mühlensiepen H, Hamacher K, Bröer S, Jansen P, Zilles K and Coenen HH: Comparison of fluorotyrosines and methionine uptake in F98 rat gliomas. Nucl Med Biol 30: 501-508, 2003.

23 Haining Z, Kawai N, Miyake K, Okada M, Okubo S, Zhang X, Fei $\mathrm{Z}$ and Tamiya T: Relation of LAT1/4F2hc expression with pathological grade, proliferation and angiogenesis in human gliomas. BMC Clin Pathol 12: 4, 2012.

24 Galldiks N, Law I, Pope WB, Arbizu J and Langen KJ: The use of amino acid PET and conventional MRI for monitoring of brain tumor therapy. Neuroimage Clin 13: 386-394, 2016.

25 Caragher SP, Hall RR 3rd, Ahsan R and Ahmed AU: Monoamines in Glioblastoma: complex biology with therapeutic potential. Neuro Oncol 20: 1014-1025, 2018.

26 Lan YL, Wang X, Xing JS, Lou JC, Ma XC and Zhang B: The potential roles of dopamine in malignant glioma. Acta Neurol Belg 117: 613-621, 2017. 